\title{
Analisis Pengendalian Kualitas Cacat Produk Kaleng 307 di PT.X Menggunakan Metode Six Sigma
}

\author{
Qoyinul Amin ${ }^{11^{*}}$, Dedi Dwilaksana ${ }^{2)}$, Nasrul IIminnafik ${ }^{3)}$ \\ 1) Jurusan Teknik Mesin Fakultas Teknik Universitas Jember \\ 2,3) Jurusan Teknik Mesin Fakultas Teknik Universitas Jember Jl. Kalimantan 37 Jember 68121
}

Naskah diterima 19 Mei 2019; direvisi 22 September 2019; disetujui 28 Oktober 2019

doi: https://doi.org/10.24843/JEM.2019.v12.i02.p01

\begin{abstract}
Abstrak
Pengendalian kualitas merupakan sebuah teknik yang dapat dilakukan mulai dari tahap sebelum proses produksi hingga proses produksi berakhir. Six sigma merupakan sebuah metodologi terstruktur untuk memperbaiki proses dengan menggunakan statistik dan problem solving tools secara intensif menuju target 3,4 kegagalan per satu juta kesempatan. PT. X bergerak di bidang industri pembuatan kaleng makanan dengan salah satu produknya adalah kaleng tipe two piece cans 307 . Berdasarkan informasi perusahaan, pada proses produksi kaleng tipe tersebut seringkali ditemukan produk mengalami cacat yang merugikan perusahaan. Penelitian ini dilakukan untuk mengetahui bagaimana cara yang tepat untuk meminimalkan cacat kaleng tipe tersebut dengan menggunakan metode six sigma. Hasil penelitian diketahui bahwa penyebab utama cacat adalah pekerja kurang teliti, setting clearence dies yang terlalu rapat, dies kemasukan afval, pisau press tumpul, bahan kotor dan rusak, perawatan mesin yang tidak dilakukan secara berkala, area produksi tidak rapi dan bising. Nilai DPMO sebesar 2844 yang dikonversikan kedalam sigma level yakni 4.27. Usulan perbaikan dengan Five-M Checklist meliputi memberikan pelatihan dan memperketat pengawasan kepada pekerja, melakukan setting mesin sesuai prosedur serta ubah clearence dies menjadi 0,24 $\mathrm{mm}$, memperketat pemeriksaan bahan baku kaleng, melaksanakan perawatan mesin sesuai dengan jadwal yang telah ditentukan, menjaga kebersihan dan kerapian area produksi.
\end{abstract}

Kata kunci: Pengendalian kualitas, Six sigma, DPMO.

\section{Abstrak}

Quality control is a technique that can be carried out from before the production process until the production process ends. Six sigma is a structured solution to process improvement using statistics and problem solving tools that intensively reach the target of 3.4 recovery per one million opportunities. PT. X is engaged in the industry of making cans with one of its products is a 307 two-piece can. Based on company information, in the production process, cans are found to find products that can save the company. This research was conducted to find out the right way to overcome this type of defect by using the six sigma method. The results of the study are known to be related to the fact that workers do not have meticulous, clear dead settings that are too tight, afval conceded dies, blunt press blades, dirty and damaged materials, machine maintenance that is not officially done, production area is not neat and noisy. The DPMO value is 2844 which is converted into sigma level which is 4.27 . Proposed improvements with the Five-M Checklist provide training and tighten supervision to workers, make machine arrangements according to procedures and change clearly to $0.24 \mathrm{~mm}$, tighten inspection of tin raw materials, manage engine maintenance according to agreed schedules, care about cleanliness and neatness production area.

Keywords: Quality Control, Six Sigma, DPMO.

\section{Pendahuluan}

Pengendalian kualitas merupakan sebuah teknik yang dilakukan mulai dari tahap sebelum proses produksi, pada saat proses produksi berjalan, hingga proses produksi berakhir. Tujuan utama dari pengendalian kualitas adalah untuk mendapatkan jaminan bahwa kualitas dari suatu produk yang dihasilkan telah sesuai dengan standar yang sudah ditetapkan dengan hanya mengeluarkan biaya produksi yang serendah mungkin.

PT. X bergerak di bidang industri pembuatan kaleng makanan dengan salah satu produknya adalah kaleng tipe two piece cans 307. Berdasarkan informasi perusahaan, pada proses produksi kaleng tipe tersebut seringkali ditemukan adanya produk kaleng mengalami cacat berupa stamping, trimming, scretch, pin hold dan pecah yang dapat merugikan perusahaan.
Six sigma merupakan sebuah metodologi terstruktur untuk memperbaiki proses yang difokuskan pada usaha mengurangi proses sekaligus mengurangi cacat (produk/jasa) dengan menggunakan statistik dan problem solving tools secara intensif menuju target 3,4 kegagalan per satu juta kesempatan untuk setiap transaksi produk [1].

Six sigma memainkan peran yang menentukan dalam pencapaian tujuan yang diinginkan serta memastikan bahwa ada pendekatan sistematis dan disiplin untuk mengatasi masalah yang dihadapi melalui tahap DMAIC [2]. Penelitian ini dilakukan untuk mengetahui bagaimana cara yang tepat untuk meminimalkan cacat kaleng tipe two piece cans $307 \mathrm{di}$ PT. X menggunakan metode six sigma.

\section{Metode Penelitian}

Penelitian ini dilaksanakan di PT. $X$ yang berlokasi di Jl. Bawean 7 Banyuwangi, Jawa timur. 
Waktu penelitian dilaksanakan pada bulan Oktober sampai dengan Desember 2018.

Pada penelitian ini objek yang dijadikan sampel adalah kaleng tipe two piece cans 307 . Variabel dalam penelitian ini yaitu jumlah kaleng tipe two piece cans 307 yang cacat dan jumlah produksi kaleng tipe two piece cans 307 pada bulan Oktober - Desember 2018.

\subsection{Metode Analisis Data}

Metode yang digunakan mengacu pada prinsip yang terdapat pada metode six sigma. Tahapan peningkatan kualitas six sigma terdiri DMAIC (Define, Measure, Analyze, Improve, dan Control) [2]. Namun pada penelitian ini hanya dilakukan tahap define, measure, analyze, dan Improve.

\section{a. Define}

Define merupakan tahap pertama dimana pada tahap ini akan dilakukan identifikasi terkait masalah kerusakan produk kaleng tipe two piece cans 307 PT. X. Cara yang dilakukan adalah:

1) Mendefinisikan spesifikasi kebutuhan pelanggan.

2) Mengidentifikasi kerusakan produk.

b. Measure

Measure merupakan tahap kedua dari peningkatan kualitas six sigma. Pada tahap ini dilakukan pengukuran dan perhitungan terhadap data hasil penelitian.

1) Analisis diagram kontrol $p$ ( $p$-chart).

a) Menghitung jumlah bagian ditolak (proporsi cacat)

$\overline{\mathrm{p}}=\frac{\text { Jumlah produk cacat }}{\text { Jumlah produk diperiksa }}$

b) Menghitung nilai Center Line (CL)

$\mathrm{CL}=\bar{P}=\frac{\text { Jumlah total produk cacat }}{\text { Jumlah total produkyang diperiksa }}$

c) Menghitung Upper Control Limit (UCL)

$\mathrm{UCL}=\bar{P}+\frac{3 \sqrt{P(1-\bar{P})}}{\sqrt{n}}$

Keterangan :

$\bar{P}=$ Rata-rata bagian ditolak.

d) Menghitung Lower Control Limit (LCL)

$\mathrm{LCL}=\bar{P}-\frac{3 \sqrt{P(1-\bar{P})}}{\sqrt{n}}$

Keterangan :

$\bar{P}=$ Rata-rata bagian ditolak.

2) Menganalisa tingkat sigma dan DPMO (Defect Per Million Opportunities).

Tabel 1 Tahap-tahap perhitungan tingkat sigma dan

\begin{tabular}{|c|c|c|}
\hline Langkah & Tindakan & Persamaan \\
\hline 1 & Proses apa yang ingin diketahui? & - \\
\hline 2 & $\begin{array}{c}\text { Berapa banyak produk yang } \\
\text { diproduksi? }\end{array}$ & - \\
\hline 3 & Berapa banyak produk yang baik? & - \\
\hline 4 & $\begin{array}{l}\text { Hitung hasil untuk proses yang } \\
\text { didefinisikan dalam langkah } 1\end{array}$ & $\begin{array}{c}=(\text { Langkah 3) } \\
\text { / (langkah 2) }\end{array}$ \\
\hline 5 & $\begin{array}{l}\text { Hitung tingkat cacat (kesalahan) } \\
\text { berdasarkan langkah } 4\end{array}$ & $=1-\underset{4)}{(\text { langkah }}$ \\
\hline 6 & Tentukan CTQ produk cacat & $\begin{array}{c}=\text { Jumlah } \\
\text { karakteristik }\end{array}$ \\
\hline
\end{tabular}

CTQ

$=($ langkah 5) /

(langkah 6)

$=($ langkah 7$)$

$\times 1.000 .000$

Hitung tingkat cacat
perkarakteristik CTQ
Hitung cacat per satu juta
kesempatan
onversi DPMO kedalam nilai
sigma
Buat kesimpulan

c. Analyze

Analyze merupakan tahap ketiga dari peningkatan kualitas six sigma. Pada tahap ini mulai menganalisa dan menentukan faktor-faktor apa saja yang paling mempengaruhi proses. Adapun langkah-langkah yang dilakukan adalah sebagai berikut :

1) Analisis Diagram Pareto.

2) Analisis Diagram Sebab-akibat.

d. Improve

Improve merupakan tahapan yang dilakukan setelah diketahui akar penyebab dari kecacatan. Pada tahap ini digunakan alat implementasi kaizen Five-M Checklist yang berfokus pada lima faktor kunci yang terlibat dalam setiap proses, yaitu man (manusia), material (bahan), machine (mesin), methods (metode), dan milleu (lingkungan).

\section{Hasil dan Pembahasan}

\subsection{Define}

Tahap define merupakan langkah pertama dalam program peningkatan kualitas six sigma. Dalam tahap ini dilakukan pendefinisian terhadap hal-hal berikut:

1) Mendefinisikan spesifikasi kebutuhan pelanggan.

Berdasarkan respon dari pelanggan, diharapkan kaleng yang dihasilkan memiliki bentuk yang sempurna tanpa cacat.

2) Mengidentifikasi kerusakan produk.

Dalam hal ini dilakukan pengamatan di area produksi dan wawancara mendalam dengan bagian kepala produksi untuk memperoleh data kecacatan produk selama bulan Oktober - Desember 2018. Dari hasil pengamatan dan wawancara ditemukan kecacatan produk pada Tabel 2 berikut.

Tabel 2. Data cacat kaleng two piece cans 307

\begin{tabular}{cccc}
\hline No & Defect & Jumlah & Persentase \\
\hline 1 & Stamping & 2213 & $33.28 \%$ \\
2 & Trimming & 715 & $10.75 \%$ \\
3 & Scratch & 823 & $12.38 \%$ \\
4 & Pin Hold & 1289 & $19.39 \%$ \\
5 & Pecah & 1609 & $24.20 \%$ \\
\hline & Total & $\mathbf{6 6 4 9}$ & $\mathbf{1 0 0 . 0 0 \%}$
\end{tabular}

\subsection{Measure}

Tahap measure merupakan langkah pengukuran untuk memperoleh informasi nilai pengukuran strategis yang digunakan pada tahap selanjutnya. Tahap ini dilakukan dengan pembuatan peta kendali $P$ dan perhitungan nilai DPMO serta level sigma.

a) Peta kendali $P$ 
Peta kendali $P$ berfungsi untuk melihat kondisi pengendalian kualitas yang dilakukan oleh perusahaan sudah terkendali atau belum. Berdasarkan pengolahan data kemudian dibuat Peta kendali P pada Gambar 1 berikut.

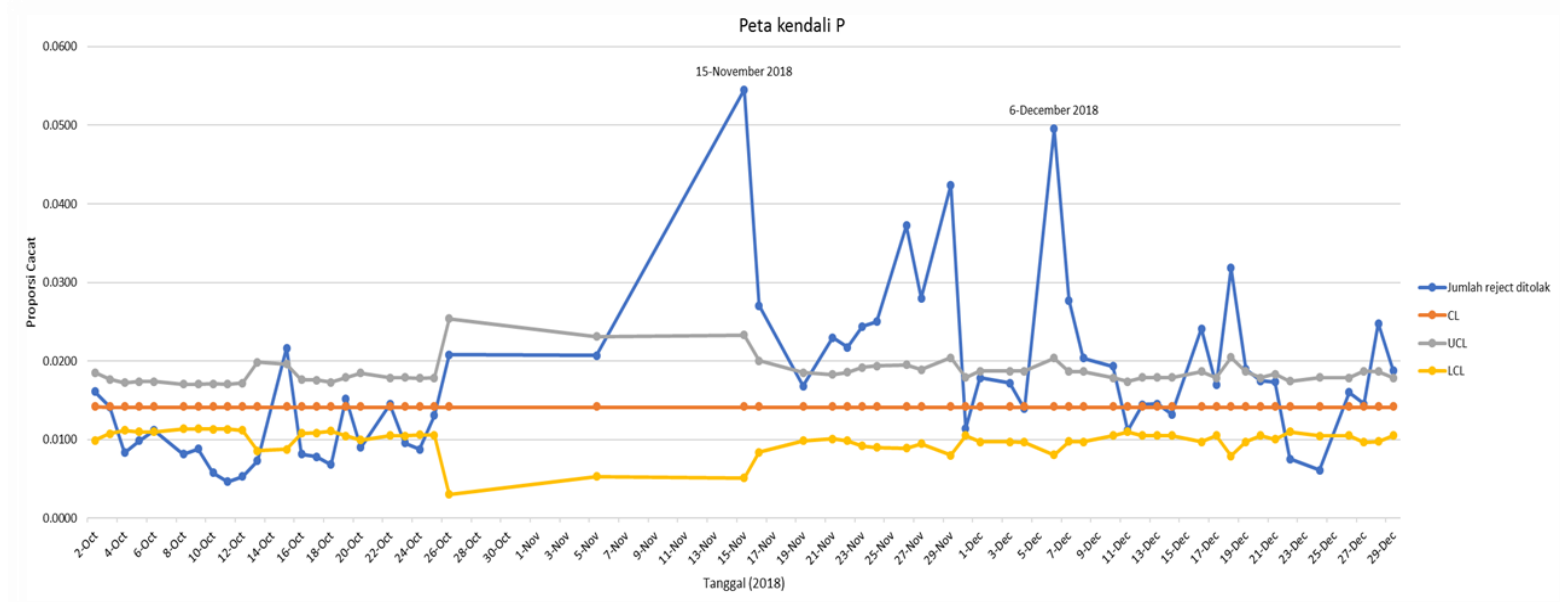

Gambar 1. Peta kendali-P kaleng two piece cans 307

Grafik peta kendali $p$ pada Gambar 1 menjelaskan bahwa tidak stabilnya pengendalian kualitas pada produksi kaleng two piece cans 307 yang terjadi pada bulan Oktober - Desember 2018 dimana terdapat titik yang berada diluar batas kendali seperti pada tanggal 15 November 2018 dimana merupakan jumlah reject tertinggi dengan jumlah produksi sebanyak 1523 unit kaleng namun dengan jumlah reject kaleng sebesar 0.0545 dan melebihi batas kendali (UCL) sebesar 0.0238 dalam hal ini yang menjadi faktor utama adalah mesin stamping yakni setting mesin yang tidak tepat dikarenakan pada beberapa hari sebelumnya mesin digunakan untuk membuat kaleng ukuran lain hal ini ditunjukkan pada diagram dimana beberapa hari sebelumnya kaleng 307 tidak diproduksi. Selanjutnya pada tanggal 6 Desember 2018 merupakan cacat tertinggi ke-2 dimana dalam produksi sejumlah 3330 unit dengan jumlah reject kaleng sebesar 0.0495 dan melebihi batas kendali (UCL) sebesar 0.0204. Faktor mesin dan manusia menjadi penyebab dari banyaknya cacat yang ditimbulkan yakni dies pada mesin stamping kemasukan afval dan menyebabkan terjadinya cacat pin hold, pada hari ini dilakukan pembersihan pada dies sehingga jumlah produksi menurun. Selain itu, kurang telitinya pemeriksaan kaleng oleh pekerja membuat banyak produk kaleng cacat pin hold yang terlewat dan terlambat untuk melakukan penanganan. Perbaikan peta kendali $P$

Perbaikan peta kendali $\mathrm{P}$ dilakukan dengan cara menghapus hari-hari yang berada diluar batas kendali (UCL) dengan tujuan untuk mendapatkan hasil yang akan diujikan pada bulan berikutnya. Perbaikan peta kendali $\mathrm{P}$ pada produksi kaleng two piece cans 307 dilakukan secara berulang hingga data yang dihasilkan berada di dalam batas kendali atau dibawah batas kendali atas (UCL). Pada Gambar 2. dapat dilihat bahwa data-data sudah berada di dalam batas kendali (dibawah batas kendali atas (UCL)). Peta kendali ini dapat digunakan sebagai acuan untuk proses produksi untuk bulan-bulan selanjutnya.

b) Perhitungan nilai DPMO dan level sigma

Berdasarkan perhitungan nilai DPMO diketahui bahwa proses produksi kaleng two piece cans 307 sebelum perbaikan memiliki nilai DPMO sebesar 2844 yang di konversikan kedalam sigma level yakni 4.27. Nilai tersebut menjelaskan bahwa dalam produksi kaleng two piece cans 307 sebanyak satu juta produk, didapatkan 2844 produk yang dihasilkan mengalami kemungkinan cacat dari suatu karakteristik CTQ yang telah ditetapkan oleh perusahaan. Berdasarkan tabel COPQ, dengan pencapaian level 4.27 berarti perusahaan berada pada standar rata-rata industri USA.

Setelah melakukan perbaikan proses produksi diharapkan kaleng two piece cans 307 menghasilkan nilai DPMO turun menjadi 1468 yang di konversikan kedalam sigma level menjadi 4.47. Hal ini menunjukkan hasil yang baik namun perlu melakukan pengendalian kualitas secara terus menerus agar dapat memenuhi target level 6 sigma di waktu mendatang. 


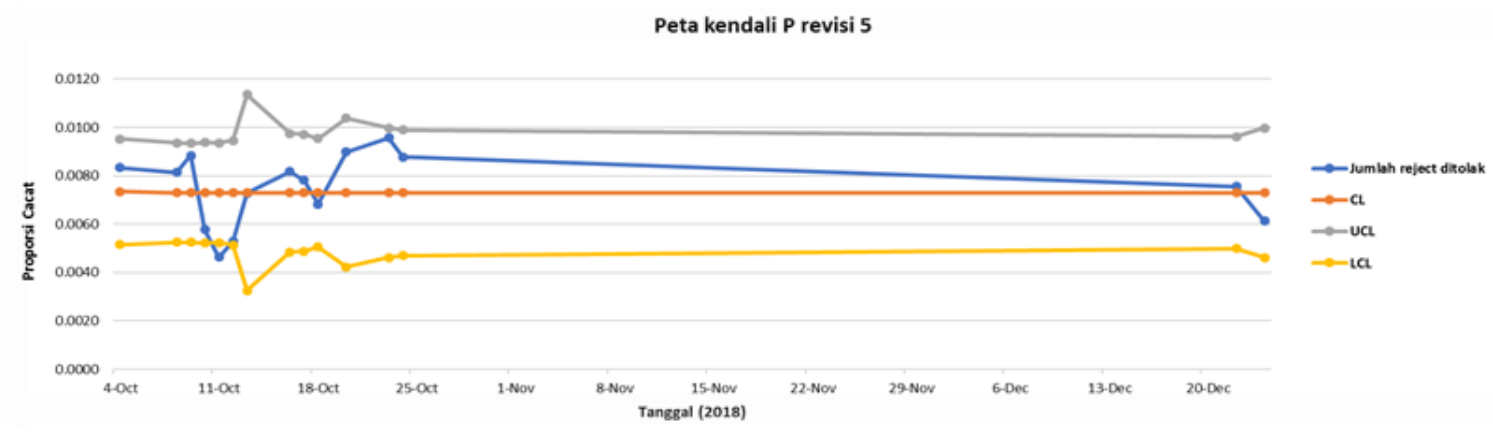

Gambar 2. Peta kendali-P kaleng two piece cans 307 (perbaikan)

\subsection{Analyze}

Pada tahap analyze digunakan 2 diagram untuk mengetahui data cacat dominan serta akar penyebab dari cacat.

a) Diagram Pareto

Diagram pareto adalah sebuah grafik yang mewakili beberapa nilai data untuk menampilkan data paling besar dan data paling kecil [3]. Dari Tabel 2 diketahui jumlah cacat kaleng two piece cans 307 kemudian dibuatlah diagram pareto pada Gambar 3.

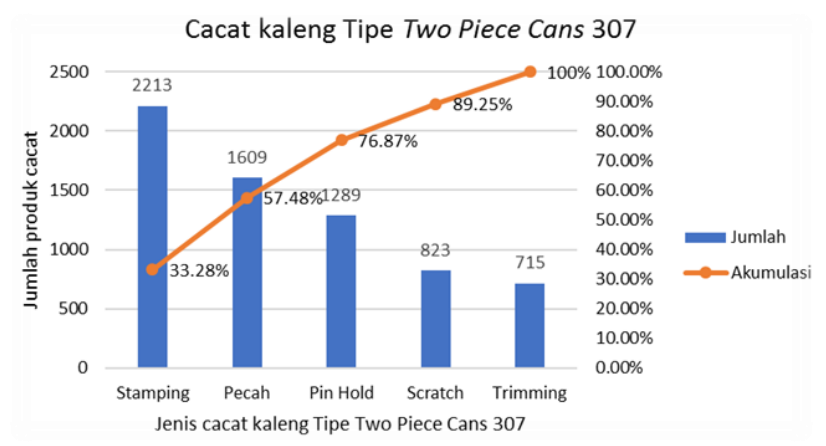

Gambar 3. Diagram pareto cacat produk kaleng two piece cans 307

Berdasarkan diagram diatas diketahui bahwa cacat stamping merupakan cacat paling dominan dengan tingkat presentase sebesar $33.28 \%$.

b) Diagram Fishbone

Diagram fishbone digunakan untuk membantu mencari akar masalah. Bila hubungan sebab-akibat masalah telah diketahui maka memudahkan penentuan tindakan pemecahan masalah [4]. Penyebab cacat dikelompokkan dalam 5 faktor utama yaitu manusia, mesin, bahan, metode dan lingkungan dengan penjelasan sebagai berikut:

1) Manusia (man)

Proses produksi melibatkan manusia untuk mengubah suatu input menjadi sebuah output. Kesalahan pekerja sangat mempengaruhi terjadinya suatu cacat produk. Kesalahan pekerja dipengaruhi ketidaktelitian dan kecerobohan, misal operator terburu-buru untuk melakukan tahap stamping sehingga ukuran diameter blank menjadi kurang dari kebutuhan yakni $148.1 \mathrm{~mm}$, yang mengakibatkan hasil produk tidak sesuai dengan yang diinginkan. Pekerja tidak mengerti mengenai mesin stamping sehingga ketika terjadi kendala pekerja tidak bisa langsung menanganinya. Selain itu inspeksi bahan baku yang kurang ketat menyebabkan bahan yang tidak baik masuk ke tahap stamping.

2) Mesin (machine)

Mesin yang digunakan untuk pembuatan kaleng two piece cans 307 di PT.X adalah mesin stamping tipe J23-110A yang berasal dari China. Mesin stamping merupakan faktor penting dalam keberhasilan proses stamping. Dies pada mesin stamping di perusahaan sering kemasukan serpihan bahan baku (afval). Afval yang berada pada dies membuat clearence antara punch, sheet metal, dan dies tidak seragam sehingga hasil stamping tidak sempurna dan mengakibatkan produk mengalami tonjolan dan lecet. Pisau pemotong yang tumpul menjadi penyebab adanya afval, hal ini karena proses pemotongan yang tidak sempurna dapat menimbulkan serpihan dari bahan baku yang kemudian masuk kedalam dies. Hal lain yang menjadi penyebab kecacatan produk adalah terlalu rapat dalam menyeting clearence antara upper dies dan lower dies pada mesin stamping dimana perusahan menerapkan clearence sebesar 0.20 dimana berdasarkan perhitungan diperoleh clearence yang sesuai adalah 0.24 sehingga pada proses deep drawing, kaleng mengalami penipisan (ironing) dan mengakibatkan kaleng pecah.

3) Bahan (material)

Bahan baku kaleng yang tidak baik mempengaruhi cacat produk. Hal ini terjadi karena inspeksi bahan baku yang kurang ketat sehingga bahan baku tidak baik terbawa ke tahap stamping. Bahan baku yang tidak baik ini meliputi bahan rusak/tergores dan kotor.

4) Metode (methods)

Metode yang mempengaruhi cacat adalah metode perawatan mesin. Perawatan yang baik pada mesin akan menghasilkan output produksi yang baik juga Selama ini perawatan mesin yang dilakukan tidak menggunakan check sheet dalam memantau kondisi mesin, hal ini dapat berdampak pada kerusakan komponen mesin yang tidak terduga. Menggunakan check sheet secara berkala merupakan salah satu metode yang cukup efektif dalam menjaga performa kinerja mesin tersebut.

5) Lingkungan (milieu)

Area kerja produksi tidak rapi dan bising disebabkan karena tidak tertatanya peralatan serta suara bising dari mesin stamping membuat pekerja tidak nyaman sehingga konsentrasinya menurun dan memicu kesalahan atau kerusakan produk. 
Dari beberapa faktor tersebut, kemudian dibuatlah diagram fishbone pada Gambar 4 berikut.

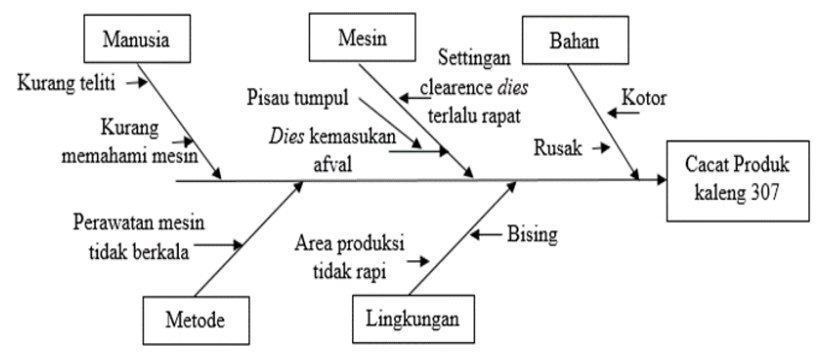

Gambar 4. Diagram fishbone penyebab cacat produk

\subsection{Improve}

Perbaikan proses untuk memecahkan masalah proses dengan tanpa mengubah struktur dasar proses tersebut. Perbaikan proses untuk memberikan rasa puas kepada konsumen, memperoleh output produk yang bermutu berdasar fakta dan data dengan berkolaborasi antar fungsi [5]. Usulan perbaikan menggunakan Five-M Checklist. Five-M Checklist merupakan sebuah metode untuk mengelola sumber daya pada kaizen [6]. Melalui brainstorming dikaji setiap $m$-faktor yang berkontribusi dalam penyelesaian masalah. Usulan perbaikan kemudian ditampilkan pada Tabel 3 berikut ini.

Tabel 3. Usulan perbaikan Five-M Checklist kaleng two piece cans 307

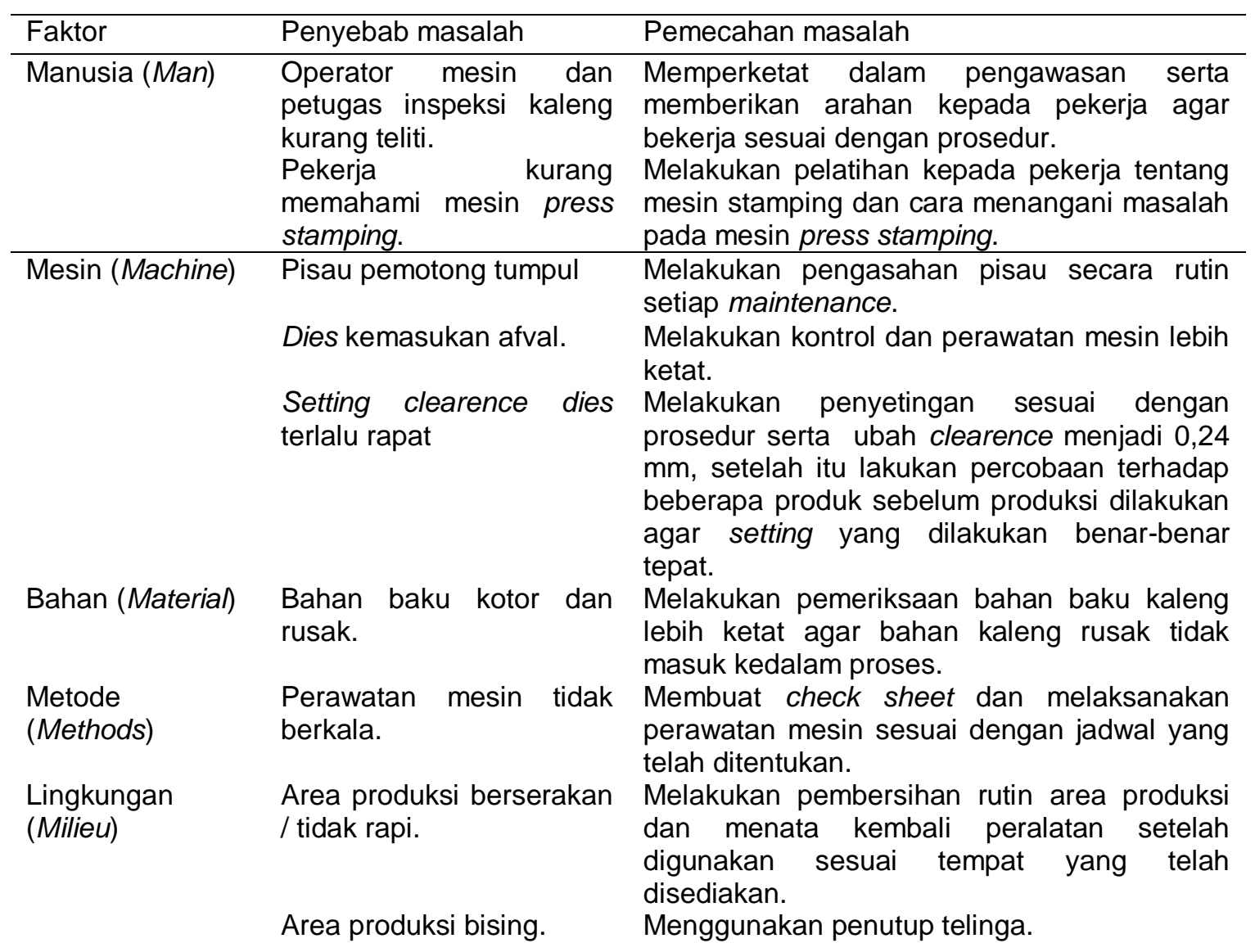

\section{Simpulan}

Dari hasil penelitian, pengolahan dan analisis data dapat ditarik kesimpulan sebagai berikut:

a. Jenis cacat kaleng two piece cans 307 paling dominan adalah cacat stamping sebesar 2213 atau $33,28 \%$ selama bulan Oktober - Desember 2018.

b. Faktor-faktor penyebab utama cacat dalam proses produksi kaleng two piece cans 307 adalah faktor manusia yakni kurang teliti dan kurang memahami mesin; faktor mesin yakni setting clearence dies yang terlalu rapat, dies kemasukan afval, dan pisau press stamping tumpul; faktor bahan yakni bahan kotor dan rusak; faktor metode yakni perawatan mesin yang tidak dilakukan secara berkala; faktor lingkungan yakni area produksi tidak rapi dan bising. c. Nilai DPMO sebelum perbaikan memiliki nilai DPMO sebesar 2844 yang di konversikan kedalam sigma level yakni 4.27. Setelah melakukan perbaikan diharapkan proses produksi kaleng two piece cans 307 menghasilkan nilai DPMO turun menjadi 1468 yang di konversikan kedalam sigma level menjadi 4.47. Hal ini menunjukkan hasil yang baik namun perlu melakukan pengendalian kualitas secara terus menerus agar dapat memenuhi target level 6 sigma di waktu mendatang.

d. Usulan perbaikan dengan Five-M Checklist meliputi memberikan pelatihan dan memperketat pengawasan kepada pekerja agar bekerja sesuai dengan prosedur, melakukan setting mesin sesuai prosedur serta ubah clearence dies menjadi 0,24 $\mathrm{mm}$, memperketat kontrol dan pengawasan mesin, 
melakukan pemeriksaan bahan baku kaleng lebih ketat agar bahan kaleng rusak tidak masuk kedalam proses, melaksanakan perawatan mesin sesuai dengan jadwal yang telah ditentukan, menjaga kebersihan dan kerapian area produksi serta menyediakan penutup telinga untuk pekerja.

\section{Ucapan Terima Kasih}

Ucapan terima kasih penulis berikan kepada PT.X yang telah memberikan izin untuk melakukan penelitian, serta kepada semua pihak yang telah membantu dalam penyelesaian penelitian ini.

\section{Daftar Pustaka}

[1] Gasperz, V. 2002. Total Quality Management. Jakarta: PT. Gramedia Pustaka Utama;

[2] Costa, T., Silfa, F. J. G., dan Ferreira, L. P. 2017. Improve the extrusion process in tire production using Six sigma methodology. Procedia Manufacturing 13: 1104-1111;

[3] Blocher, E. J. 2007. Manajemen Biaya 2. Jakarta: Salemba Empat;

[4] Hidayat, A. 2007. Strategi Six sigma. Jakarta: PT. Elex Media Komputindo;

[5] Purnawanto, B. 2010. Manajemen SDM Berbasis Proses. Jakarta: Grasindo;

[6] Imai, M. dan Gandamihardja, M. 1991. Kaizen (Ky'zen) Kunci Sukses Jepang Dalam Persaingan. Jakarta: PT Pustaka Binaman Presindo. 